the higher branches of mathematic" is not a vain hope. $\mathrm{He}$ could not, in our opinion, have made a better beginning. If our critical responsibility compels us to point out some defects in the execution of the work, we trust that this will be understood as indicating our desire to see the book made perfect; and not construed into depreciation of a valuable service to the cause of pure mathematics.

We strongly advise the author to have the translation read by some one who is familiar with both English and German idioms, and who possesses also some familiarity with the departments of mathematics concerned. In proof of the necessity for such a revision, we draw the author's attention to the following points, which are merely a few of those that have attracted our attention. When Klein says (Pt. I. chap. iii., \$ 7), "Die Lineare Differentialgleichung zweiter Ordnung, verlangt also, . . , zu ihrer Lösung nur noch eine einzige Quadratur ; " he does not mean, "The linear differential equation of the second order, therefore, requires, ...., only a single square root besides in order to solve it." Quadratur means simply quadrature (i.e., direct integration), it never means square root. Here a knowledge of the properties of the Schwarzian derivative might have helped the translator to divine the meaning of the German technical term. On p. 96, "But for this the determination of the R's themselves is more easy to carry out," is not a good, but in fact a misleading translation of the German "Dafür aber ist die Bestimmung. . ." Dafür here means "in compensation for this." At the foot of the same page occurs a very common confusion between wenn eben and wenn gleich, which has the effect of exactly reversing the meaning of the note. "Hierdurch kann $f(x)=o$ (wenn eben $\gamma$, in den $x$ geschrieben, nicht transitive ist) möglicherweise reducibel geworden sein," means, "Hereby $f(x)=0$ may possibly have become reducible (namely if (or precisely if) $\gamma$, when expressed in terms of the $x^{\prime}$ s, is intransitive) "for, of course, an equation is reducible if, and not unless, its group be intransitive. A still more important error occurs on the following page, where, in the definition of the Galois resolvent, "ihre einzelne Wurzel bei jeder in G enthaltenen Vertauschung der $x$ umgeändert wird" is translated "its individual roots are unaltered, \&c." First of all, this makes nonsense of the definition, as definite knowledge of the subject would have shown; and farther, supposing the translator to have read $u n$ - by mistake for sm -, a knowledge of German idiom would have shown him that "ungeändert wird" makes nonsense of the German. The error is deliberately repeated on the following page, where " in umgeänderter Reihenfolge" is translated in "unaltered sequence," instead of "in altered sequence." These are vital errors, which should at once be corrected by means of an "errata-slip"; for they would be a serious rock of offence for a tyro in reading the passages where they occur. There are many other cases, however, where loose translation somewhat obscures the crisp and lucid exposition of Klein, which is a pity, for this quality is not all too common among Klein's countrymen. There are a considerable number of misprints, many of them copied from the original. An amusing instance of this occurs in the first footnote on p. 73 , where the title of Schwarz's well-known memoir begins "Ueber dienigen Fälle, \&c." ; this is in the original, but the transcriber should have known that dienigen is impossible German. Nevertheless, we declare, with all the sanction of our critical stool of infallibility, that $\mathrm{Mr}$. Morris's translation is a notable piece of good work; and he did well to publish it without waiting to perfect his knowledge of German idiom or of Galois's theory. The blemishes alluded to can be easily amended when another edition is called for, which will be speedily, if our good wishes avail.

G. CH.

\section{THE NORTHFLEET SERIES ELECTRIC} TRAMWAY

N Monday, April 29, there was opened for regular passenger traffic an electric tramway at Northfleet, near Gravesend, which marks an era in the history of electric traction. This line has been run experimentally for the last month, but the seven years Board of Trade certificate having been received, this line now enters on the commercial stage of its existence. Four tramways on which electricity is the motive power have been in regular use for the last few years in Great Britain: it is not, therefore, because the Northfleet line is the first electric tramway in this country that it has attracted considerable attention; nor is it because it is the longest electric tramway, for two of the other four are of much greater length; but it is because this Northfleet line has been constructed on a totally different principle from that hitherto adopted on this side of the Atlantic that it is worthy of special consideration.

When a number of electric lamps or motors have to be supplied with power from a common centre, there are two well-known methods by which this can be done. They can either be joined "in parallel," as it is technically called, or they can be coupled up "in series." In the parallel system, the one generally adopted with electric lighting, and hitherto the only method that has been employed with the electric tramways in Europe, the electric current that passes through any lamp or motor does not pass through any other, and the dynamo produces a large current equal to the sum of all the currents passing through all the lamps or motors. In proceeding, therefore, from the dynamo end of the circuit to the distant end, there is a steady falling off in the current, but the electric pressure remains, or may remain, nearly constant. In the series system, on the other hand, the whole current produced by the dynamo passes through all the lamps or motors in succession, and therefore this current can be small. The initial electric pressure, on the other hand, must be large, since the energy imparted by the current to each lamp or motor is represented by a drop in the electric pressure. Since the energy furnished by the dynamo depends on the product of the current into the electric pressure it produces, while the waste of power in heating the conductor depends on the square of the current flowing through the conductor, it is clear that while any amount of energy can be supplied by either system, the use of high pressure and small current is by far the more economical as regards the power wasted in heating the conductor, this economy being the greater the greater the number of lamps or motors on the circuit.

Until a few years ago, however, it was not clear how it was possible to run motors electrically in series when the motors were themselves in bodily motion, as they must be when employed to propel tramcars. In $188 \mathrm{r}$, Profs. Ayrton and Perry, for the purpose of diminishing the loss of power through the leakage of the current that occurs from the insulated rail of an electric railway to the earth, and which becomes serious when the line is long, proposed a plan of electrically subdividing the railway track into sections so arranged that the electric current was only supplied to that section of the track on which a train happened to be at any moment. This system was described and shown in action at a lecture given by one of the inventors at the Royal Institution in I 882, and the late Prof. Fleeming Jenkin, on reading the account of this lecture, saw that the device of employing an electrically subdivided conductor supplied the means of running electrical trains in series. A combination was, therefore, brought about between these three Professors to develop electric traction. This combination resulted in the formation of the Telpherage Syndicate, and lastly in the Series Electrical Traction Syndicate, to whom is due the construction of the first series line in Europe, the 
one that was opened for public traffic at Northfleet, on April 29.

The track itseif does not at first sight appear to differ from an ordinary horse tramway track, there being no overhead wires as in the American electric tramways, nor auxiliary raised insulated rail, as at Portrush, nor central trough, as at Blackpool. A closer inspection, however, shows that one of the rails at Northfleet, instead of being simply grooved, is a double rail with a cavity or slot between the two portions. Fig. I shows the general cross-section of the line, the upper portion only of which is of course visible to the passer-by. In the cavity "the arrow," as it is called, glides, being drawn along by the moving car, the function of the arrow being to open the electrical

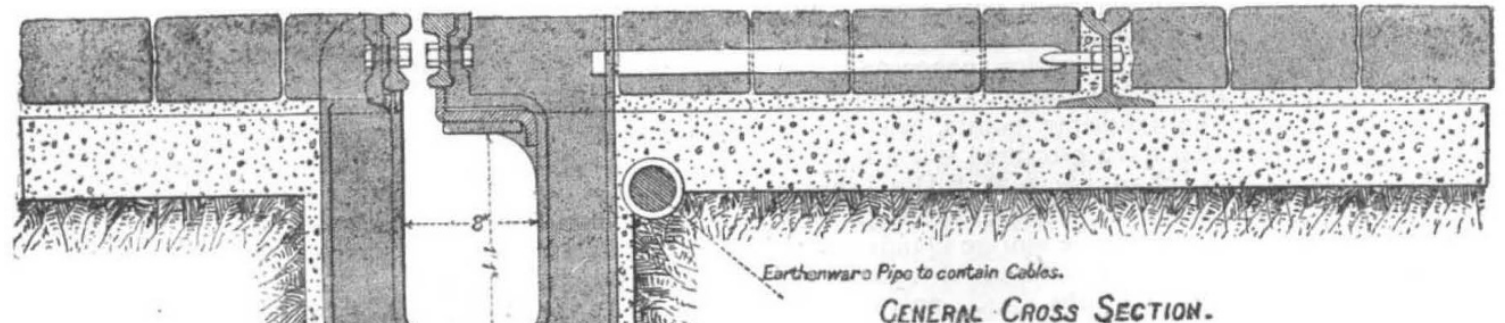

Fig. I.

conductor at successive points, and insert the electric motor carried by the moving car in the electrical circuit. This arrow is made of flexible leather with a kind of steel spear-head at each end; it is coated with two flexible conducting strips, I, 2 (Fig. 2), insulated from one another: and permanently connected respectively with the two terminals of the motor. As this arrow glides along, it passes, as seen in Fig. 3, between the two portions of each spring-jack, the spring-jack being shown in detail in Fig. 4. The arrow keeps open two springjacks at any one time, the portion of the cable joining them being either cut out of circuit or short-circuited, its place in the electric circuit being temporarily occupied by the motor on the car. This result is attained by the con-

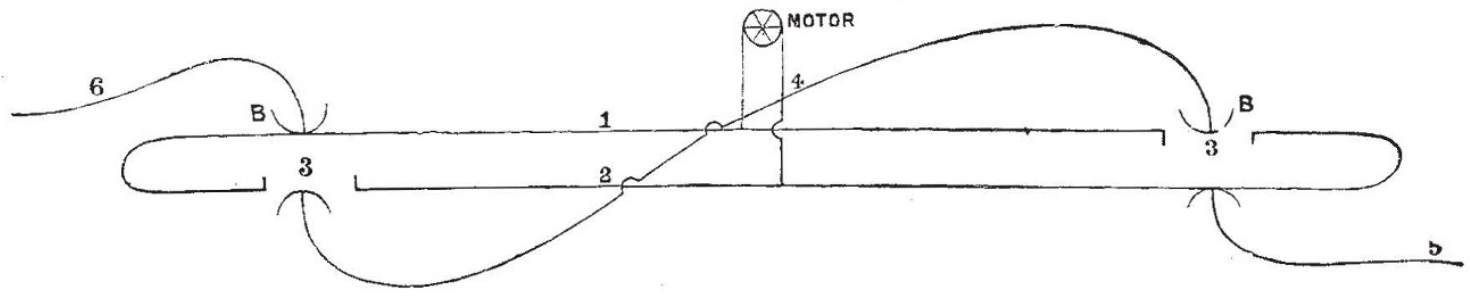

FIG. 2.--The Arrow.

ducting-strips $\mathrm{r}, 2$ (Fig. 2) on the arrow, being each wrapped round one end, and by an insulated space, 3,3 , being left on each side, slightly longer than the surface of contact $B$ of the spring-jack. When the sceptical Englishman, who, in the past, could not realize that railways could ever succeed if the carriages were not shaped and painted like mail-coaches, reads a description of the
Northfleet series tramway, he at once jumps to the conclusion that stones must necessarily get wedged in the slot; that the cavity will get filled up with mud; that the arrow must stick; and that the method is impossible in practice, though very pretty in theory. When he is told that a series electric tramway has been running successfully for some time in Denver, Colorado, and that

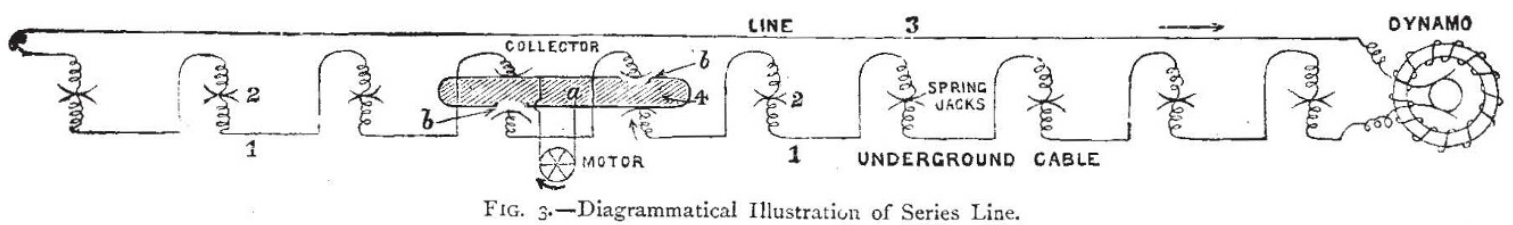

another series line, twelve miles long, with forty cars on it, is completed, or on the verge of completion, in Columbus, Obio, he merely shrugs his shoulders and implies that such crude ideas may do for America, but that in this country we want time-honoured well-tried methods, and not new-fangled notions. The Northfieet cars, however: seem to have a marked disreyard for conservative prejudices, since the arrow, with an ease and lofty contempt that makes one respect the silent power of the electric current, simply whisks out of its way any stone that has been intentionally jammed into the slot as tightly as any mischievous London urchin can fix it.

The spring-jack (Fig. 4) consists of a pair of glazed earthenware blocks, $14 \times 3 \times 4$ inches. To each block 
is attached, by means of a double spiral spring, a gunmetal casting, curved at its ends to allow of the easy entrance of the arrow. The spring-jacks are arranged so that they can be taken out or replaced in the conduit in a few minutes in case of any failure. The electric resistance that they offer is much smaller than would have been anticipated, the total measured resistance of the entire line being but little higher than the calculated re-

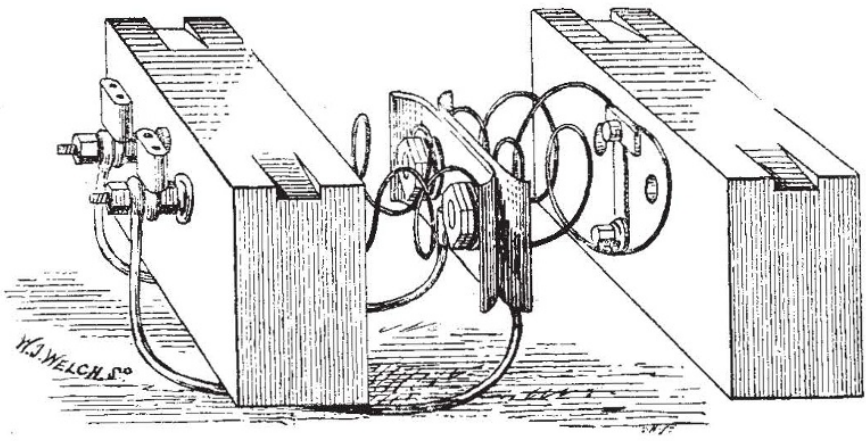

FIG. 4.-The Spring Jack.

sistance of the insulated cable. This is probably due to the surfaces of the spring-jacks being kept bright and clean by the arrow constantly running through them.

In order that the speed of any one car shall not be affected by the starting or stopping of any other, it is necessary, with series working, that a constant current should be supplied to the circuit. Now while it is possible, by winding the field-magnets of a dynamo in a

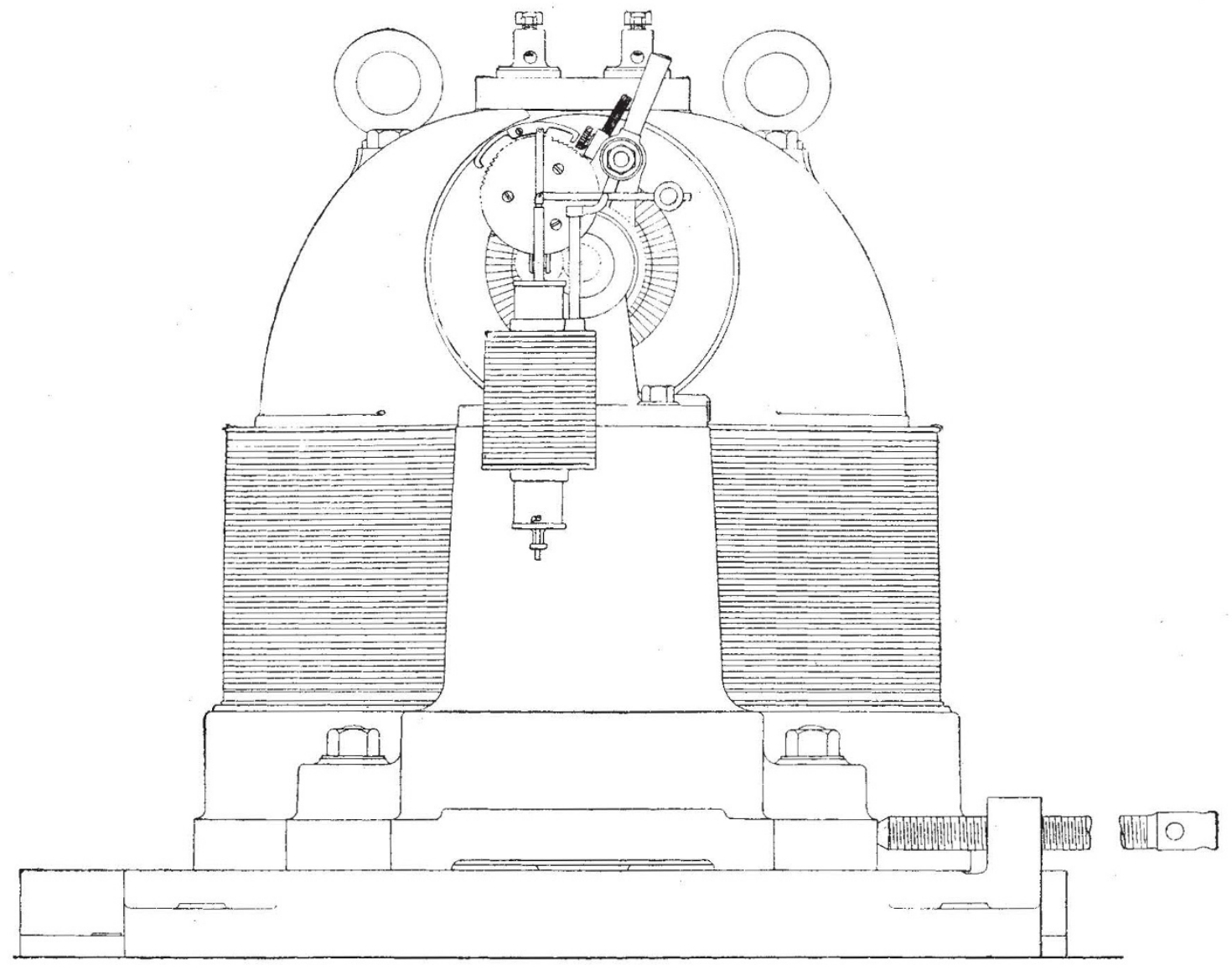

FIG. 5.-The Statter Constant Current Dynamo, showing Regulator.

particular way, known as "compounding," to cause it, when running at a fixed speed, to supply perfectly constant pressure to a circuit, no matter how the resistance of the circuit may vary, no such solution has yet been practically attained when the supply conditions are contstant current. Hence some mechanical device is necessary in the latter case, and the one employed with the Northfleet dynamo is that due to Messrs. Statter, and 
seen in Fig. 5. A small pinion rotated by the dynamo shaft rocks a double ratchet by means of an eccentric. One or other of the ends of this ratchet is pulled down and made to engage with the ratchet wheel depending on whether the current is greater or less than 50 amperes, the normal current supplied to the line. The rotation of the ratchet wheel alters the positions of the brushes on the commutator, until the current is diminished or increased to 50 amperes, when the iron core attached to the ratchet, and which was previously sucked down below its normal position by the solenoid, or not sucked down so far, is now held in its normal position, and the ratchet kept free of the ratchet wheel. This mechanical constant current regulator works well, with a surprisingly small amount of sparking at the commutator.

As constant current is supplied to the line, the speed of the car could not be altered by introducing resistance into the circuit; what is done therefore is to shunt the field magnets of the motor with a less and less resistance by moving a lever on the car, as less and less power is required to be developed by the motor. When the car is at rest at the end of the journey, the motor is entirely cut out of the circuit by the handle being pushed full home. With horse tramcars a mechanical brake must be employed, and the energy of the moving car wasted in friction ; indeed with the continuous vacuum brakes on the modern railway trains, not merely is the energy of the train wasted, but coal is actually burnt to stop the train. Some years ago, however, Profs. Ayrton and Perry pointed out that when an electric train was running down hill, or when it was desired to stop the train, there was no necessity to apply a mechanical brake and waste the energy of the moving train in friction, because by turning a handle the electromotor could be converted into a dynamo, and the train could be slowed or stopped by its energy being given up to all the other trains running on the same railway, so that trains going down hill could help the trains going up hill, and the stopping trains could help the starting trains. And at that time they proposed detailed methods for carrying out this economical mutual aid arrangement whether the trains were running in parallel or in series. But there is this great difference between the two systems, that whereas with motors in parallel it is only as long as a stopping train is still running fairly fast that it can help other trains; on the other hand, when one of a group of motors in series has been temporarily converted into a dynamo by the reversal of the conncction of its field-magnets, this motor can return energy to the system down to the very last rotation of its armature. This difference, which is greatly to the advantage of the series system, will be easily understood if it be remembered that a motor will help other motors in series with it if it supplies a forward electromotive force, however small, whereas if the motors be in parallel it is necessary, in order that a motor should give energy to the system, that it should be able to reverse the direction of the current that was previously passing through it-in other words, produce an electromotive force actually larger than the potential difference set up between the mains by the dynamo itself.

And not only is this form of brake very economical in that it acts by saving power instead of by wasting it, but in addition its application imposes no tax on the driver's strength, as is the case with mechanical brakes where the pressure of the brake blocks is actually exerted by the driver's hand or foot-a consideration of considerable importance in these days of the natural revolt of the "tram slave."

At each end of the Northfleet cars there are two handles, one of which regulates the resistance shunting the field-magnet of the motor, and which therefore replaces the handle working the throttle valve of a steam loco. motive, while the other handle reverses the terminals of the field-magnet, or short-circuits them when it is in its middle position, and therefore replaces the handle which operates the link motion in the locomotive. During the several journeys we made in the cars, we had frequent opportunity of seeing how perfectly they were under control, even when descending the steep hill near the Northfleet railway station.

One defect of the parallel system of working electric tram-lines is that it is possible for a mischievous person to cut off the power from the whole line, while at the same time the constant potential difference dynamo is made to produce far more than its normal current, by his laying an iron crowbar so as to electrically connect the go:ns and return conductor. This result he may be able to accomplish without much difficulty, since both these conductors must be sufficiently exposed along their whole length that the passing train can maintain electrical contact with both of them. With the series system, on the other hand, such a catastrophe is impossible, since the return conductor, 3, marked "line" in Fig. 3, is completely buried out of sight.

A considerable amount of ingenuity has been displayed in the mechanical details both on the cars themselves and on the track at Northfleet. The motor, for example, is geared directly to a spur wheel on the car wheel shaft by double helical gearing, which runs without biting, and at the same time without any chance of slip, since the axle of the motor and the axle of the car wheel driven by it are always maintained at exactly the same distance apart. The result is attained by supporting one end of the motor framework from two bearings on the axle of the car wheel, and the other end by stout springs from the car itself. The tram-line is for the greater portion a single track, hence several places where the up and down cars can pass, "turn-outs" as they are technically called, have been provided. As both the up and down lines at the turn-outs are electrically in series, special electrical devices which appear to work very well have been provided for the facing points at the two ends of each turnout. At one portion of the line the road is so narrow that it would have been very inconvenient to the ordinary horse traffic, had an up and a down tramcar gone along the same side of the road. An up car has therefore to pass the horse traffic by following the "near side," so also has a down car-in other words, the electric tramcar if it be going in one direction has to be on the opposite side of the road from that followed by an electric tramcar when going in the contrary direction. But as the road is too narrow for two sets of rails the track here consists of three rails, $\mathrm{A} B$ and $\mathrm{C}, \mathrm{A}$ and $\mathrm{B}$ being used by the car when going in one direction, and $\mathrm{C}$ and $\mathrm{B}$ when it is returning : the facing points at the ends of this section being fitted with special mechanical and electrical devices, which also appear to accomplish their aims with perfect satisfaction.

A portion of the line has a long steep gradient of $I$ in 32 , but instead of jaded horses having to tug the cars up this hill, they ascend it at a rate of about nine miles an hour, so that the whole journey, which is a little under one mile, is accomplished when desired in three minutes and a half.

It is but a few weeks ago that the first trial trip of the Northfleet line was made ; it is but now that it is opened for public use; and yet already the passers-by and the shopkeepers along the route have ceased to wonder how it is that horseless cars full of people rush up hill without smoke, quickly start in either direction, and as quickly stop when directed by the passengers to do so. After the Englishman has been spending some time conclusively proving to himself that a series tram-line was a practical impossibility, while the American was engaged in carrying out the trite saying that "the best way to do a thing is just to go and do it," our countrymen now accept the regular daily running of the series tram-line at Northfleet as a matter of course, and have forgotten that its very marked success ought to astonish them. 